\title{
Influence of Parental Mental Health on Early Termination of Breast-Feeding: a Case-Control Study
}

\author{
Olga Garcia Falceto, Elsa R. J. Giugliani, and Carmen Luiza C. Fernandes
}

Background: The WHO recommends exclusive breast-feeding for babies up to 6 months of age. The association between maternal mental health and breast-feeding duration is contradictory. This is a casecontrol study to investigate this association.

Methods: 153 families with 4-month-old babies from an urban area in southern Brazil were investigated: in 51 families, breast-feeding had being discontinued (cases); in 102, babies were being breastfed (controls). Two researchers evaluated maternal and paternal mental health during home visits using semistructured interviews and scales.

Results: Disorders were found in $59 \%$ of case mothers versus $48 \%$ of control mothers. Depression was the most prevalent disorder affecting both mothers and fathers. We did not identify a statistically significant association between maternal mental disorder at 4 months after delivery and early termination of breast-feeding. When the mother had mental problems during the first month after delivery, however, she was twice as likely to interrupt breast-feeding. Among the mothers with mental disorders during puerperium, $76 \%$ still had the problem 4 months postpartum. An association was observed between maternal and paternal mental health.

Conclusions: Parental mental health does not seem to be associated with breast-feeding at 4 months in this culture setting where most mothers have good family and social support for breast-feeding. Maternal mental disorders during puerperium, however, may negatively affect the duration of breastfeeding. (J Am Board Fam Pract 2004;17:173-83.)

Studies concerning the association of maternal depression and breast-feeding present contradictory findings. Most report shorter breast-feeding duration in the presence of postpartum depression, ${ }^{1-10}$ although some have not found any correlation between these 2 events. ${ }^{11-13}$ Other studies show a higher prevalence of postpartum depression in breast-feeding women, ${ }^{7,14,15}$ and several clinical reports describe cases in which breast-feeding was interrupted as a result of maternal depression. ${ }^{1,6,16-19}$ Still other studies have identified an association between maternal anxiety and shorter duration of breast-feeding. ${ }^{20}$

Two main postpartum mood problems are described in the literature: postpartum blues and

Submitted, revised, 2003 November 18.

From the Departments of Psychiatry (OGF) and Pediatrics (ERJG), School of Medicine, Universidade Federal do Rio Grande do Sul, Brazil, and the Community Health Service, Grupo Hospitalar Conceição, Brazil (CLCF). Address correspondence to Olga Garcia Falceto, Rua João Abbott, 451/402, 90460-150 Porto Alegre, RS-Brazil (email: ovidolg@uol.com.br).

This work was supported by the Research Incentive Fund (FIPE). postpartum depression. Postpartum blues affects 25 to $76 \%$ of mothers in the first 10 days postpartum. ${ }^{21}$ There is no consensus about the existence of an association between postpartum blues and postpartum depression, although some investigations show that 21 to $25 \%$ of the mothers affected by postpartum blues develop depression. ${ }^{6,11,21}$ Postpartum depression usually begins in the first 3 months after delivery and affects about 10 to $15 \%$ of mothers ${ }^{22}$ or up to $24.5 \%{ }^{23}$ and it is described as frequently lasting for more than 1 year. $^{24}$

Among the mothers with psychiatric problems in the postpartum period, 50 to $75 \%$ of them suffer from affective disorders, $12 \%$ from anxiety, 10 to $20 \%$ from schizophrenia, and 2 to $12 \%$ from organic psychiatric disorders. ${ }^{16,24,25}$ In addition, men have been reported to present a cumulative incidence of paternal depression in the first year after childbirth: $23.8 \%$ in a Portuguese study, ${ }^{23}$ and $10.1 \%$ in an Australian study. ${ }^{26}$ In those 2 studies, the onset of the disorder was usually observed at 3 months after childbirth. Men who live with depressive women have a higher chance of becoming depressed, and vice versa. ${ }^{23,25}$ 
To date, however, no study has investigated the existence of a relationship between the mental health of both the father and the mother and discontinuation of breast-feeding. The objective of the present study was therefore to investigate the existence of an association between termination of breast-feeding before 4 months and parental mental health in an urban area in southern Brazil.

\section{Methods}

We performed a case-control study of families with 4-month-old babies: in 51 families (cases), babies were no longer being breast-fed, and in 102 families (controls), babies were being breast-fed (exclusively or not). The age of 4 months was defined as the cutoff point for early weaning. This is a cutoff point often used in the literature, including local studies. $^{27-29}$

The study population was drawn from among the 18,000 inhabitants of an urban area in the city of Porto Alegre, south Brazil. This area is economically heterogeneous, housing mostly lower middle class-but a few very poor-families. A large public hospital, Grupo Hospitalar Conceição (GHC), is in charge of the 3 outpatient clinics in the area, which are served by family physicians. All the households have running water and electricity, but some are not served by a sewage disposal system and garbage collection. All streets are paved, except for a few alleys where public safety is a serious problem.

The selection of families followed a strict methodology. Records of births in Porto Alegre hospitals were checked to identify families with babies younger than 4 months living in the area. When the baby reached the age of 4 months, a medical student visited the home to ask the family to take part in the study and to perform a preliminary interview. The team of interviewers received intensive training, after which a pilot study was conducted with 10 families. All the interviewers and medical students involved contributed to the final version of the questionnaire. The senior investigators (OGF and CLCF) also conducted interviews, pairing up with different interviewers to ensure the reliability of information. All data were entered twice and checked to rule out possible input errors. The Research Ethics Committee at GHC approved the study protocol. The analysis presented is this article is part of a larger study of psychosocial aspects involved in child and family health. The research team was blind to the specific questions under study.

Sample size was calculated for a 1:2 ratio. Our initial hypothesis was that about $60 \%$ of the mothers of babies weaned early would present some type of emotional disorder, whereas $30 \%$ of those still breast-feeding would present emotional problems. This hypothesis was based on an epidemiologic study of the population in Porto Alegre, ${ }^{30}$ according to which $48 \%$ of the general adult population has some type of psychiatric disorder (when nicotine abuse is included as one of the diagnoses) and on studies that indicate that the puerperium is the period during which women are at highest risk for developing mental disorders. ${ }^{16}$ In the present study, an $\alpha$ error of 0.05 and a $\beta$ error of 0.20 were considered.

We planned to include, at the most, the first 5 cases (that is, babies who were no longer breastfeeding at the time of the first visit) identified each month, and the 2 families that immediately followed the case-family in the list of births, and whose babies were still being breast-fed, until the sample was complete. Following this method, we ended up visiting all the families who lived in the study area and had 4-month-old babies in the period between March 1999 and May 2000. The families of 16 babies were excluded after a preliminary interview: 3 sets of twins, 6 babies of mothers who were $\mathrm{HIV}$-positive, 2 babies who were deceased, 1 baby being fed through a nasopharyngeal tube, and 1 baby whose mother was taking a medication that prevented her from breast-feeding. Seven families refused to provide any type of information. Thus, 215 families answered at least the preliminary interview.

When the family agreed to participate in the study, both parents (or the mother only, when the parents were separated) signed an informed consent form. A home visit was then scheduled. The interview was conducted by 2 family therapists and videotaped by a medical student. The 2 interviewers recorded their impressions and rated the scales independently. If a family was not found at home after 3 attempts, it was replaced with the next family on the list.

Home visits lasted about 2 hours and were divided into 3 parts. First, the interviewers held a preliminary conversation that sometimes included grandparents, other relatives or friends living in the same household or visiting at the moment of the 
interview. Then, the 2 parents were interviewed together; finally, each parent was interviewed individually. Of the 153 fathers, 120 were cohabiting with the mother of their child and, of these, 118 were interviewed. The other 2 were working out of town. Of the 33 not cohabiting, 3 were interviewed, giving a total of 121 fathers interviewed. Of those not cohabiting and not interviewed, 19 had lost contact with their babies, 2 were deceased, 1 was in jail, and 1 was hospitalized for long-term psychiatric treatment.

The first part of the interview with the parents focused on the birth and its impact on the life of the family and parents, on the baby's feeding, and on the breast-feeding support provided by the father (expressing their approval of breast-feeding, knowing its importance for the baby's health, praising the wife and facilitating the practice of breast-feeding) and by the parents' families and social network. In the second part, the couple's relationship and social network were discussed. The genogram for each couple was drawn, including previous marriages and children from other relationships, with a description of both parents' families, their medical and psychiatric histories, and similarities and differences in the way the couple and their families functioned.

In the third part, each therapist held an individual conversation with 1 of the parents. It started with an open conversation and moved on to questions about the pregnancy and delivery, about the interviewee's relationship with their partners, about their sexual life and their conflict resolution strategies, including questions about domestic violence, and about their relationships with relatives, friends, the broader social network, and the health care and justice systems. Questions also covered topics relating to personal history, to the partner's medical and psychiatric status, to alcohol and drug use, and to past and present psychiatric hospitalizations and use of psychotropic drugs.

Each parent individually completed the 20 -question version of the Self-Reporting Questionnaire (SRQ-20). A cutoff score of 7 or more for women and 5 or more for men to indicate probable mental disorders was used based on the validation of the SRQ in Brazil. ${ }^{31}$

After completing the diagnostic process, each interviewer assessed independently the level of emotional functioning of the mother and father in daily life and in their main relationships, according to a modified version (we included the evaluation of the emotional state) of the categorical version of the American Psychiatric Association's Diagnostic and Statistical Manual of Mental Disorders (DSMIV) ${ }^{32}$ Global Assessment of Relational Functioning (GARF) Scale, which scores relational functioning using a five-level scale, from $1=$ no evidence of emotional difficulties to $5=$ important emotional difficulties that seriously affect everyday life and relationships. The sample was then divided into 2 groups: without or with minor disorders (scores 1 and 2), and with moderate to severe disorders (scores 3 to 5). Scores for emotional functioning were determined for present functioning (in the past 2 weeks), functioning during puerperium (defined as the 1st month postpartum), and past functioning (history of psychiatric disorder any time before delivery).

The 2 interviewers discussed and agreed on a diagnosis for each parent based on DSM-IV criteria. ${ }^{32}$ Nicotine abuse was researched but not considered when it was an isolated diagnosis, because we found no association between it and early weaning. If there was disagreement, the case was discussed again with the principal investigator (OGF) until a consensus was reached. If necessary, the video of the interview was reviewed.

The Student's $t$ test was used to analyze continuous data comparing the case and control groups, and the $\chi^{2}$ test and odds ratio were used for categorical data. At the end of the analysis, a logistic regression test was used to control the effects of possible confounding variables on the association between mental health and breast-feeding. The variables entered into the model were those that were statistically associated $(P<.2)$ with the baby's type of feeding at 4 months in the bivariate analysis, except for father's age and number of children, because these 2 variables were highly correlated with mother's age and baby's birth order. The Statistical Package for the Social Sciences (SPSS Inc., Chicago, IL) was used for the statistical analyses.

\section{Results}

Of the 222 families that met the inclusion criteria, 7 refused to talk to the interviewers and 62 completed only the preliminary interview. The 62 families that answered only the preliminary interview were compared with the 153 families that com- 
pleted the study to investigate selection bias. The following characteristics were analyzed: age, schooling, skin color, parents' occupations, whether the parents lived together, method of delivery, length of gestation, sex of the baby, birth weight, hospitalizations, household conditions, and socioeconomic class. The number of nonwhite men $(P=.016)$ and low-weight babies $(P=.001)$ was significantly higher in the group that did not complete the study, but neither of these variables was associated with breast-feeding at 4 months.

Mean maternal age of the study population was 26 years (range, 14 to 45 years). Mean paternal age was 30 years (range, 17 to 62 years). Mean period of schooling was $6.6 \pm 2.9$ years among mothers (range, 1 to 14 years) and $7.6 \pm 7.4$ among fathers (range, 0 to 18 years). Most subjects in our sample were white $(58 \%$ of the women and $60 \%$ of the men), and $86 \%$ of the mothers had had the recommended number of prenatal visits (5 or more). The mean number of children per family was 2.2 , and the largest family had 8 children. Seventy-eight percent of the couples lived together. Household conditions were adequate for $91 \%$ of the families; that is, they had electricity, running water in the house, and sewage system. Seventy-six percent of the mothers were not currently working; $75 \%$ of the fathers had a job, and the other $25 \%$ made a living doing odd jobs. Median family income was 3.6 (range, 0 to 16.9 ) minimum wages (about US $\$ 280$ per month). Four families (2.6\%) described themselves as having no steady income.

The mean birth weight of the babies was $3240 \mathrm{~g}$. Most were born at term by vaginal delivery. While in the hospital, $75 \%$ of the babies and their mothers roomed in (in Porto Alegre all major public maternities are Baby Friendly Hospitals; therefore, healthy mother-child diads are expected to room in). Nine babies were later separated from their mothers because of maternal hospitalization.

Table 1 presents a comparison of the characteristics of the 2 groups involved in the study. A significant association was observed between breast-feeding at 4 months and the following factors: (1) younger mothers and fathers, (2) mother's first child, (3) less than 4 children in the family, (4) mother rooming in with the baby, and (5) mother not being separated from the baby. Of the 102 breast-fed babies, 29 (28.4\%) were exclusively breast-fed at 4 months (receiving only breast milk and no other liquid or solid), and 73 (72.6\%) were partially breast-fed. Of the babies who were no longer breast-fed, $23(45.1 \%)$ were weaned in the 1 st month, and 15 (29.4\%), 12 (23.5\%), and 1 (2\%) in the $2 \mathrm{nd}, 3 \mathrm{rd}$, and 4 th months of life, respectively.

Eighty-five percent of the 121 fathers interviewed said that they considered breast-feeding very important for the baby; all the others considered it important. None of the fathers made any negative remark about breast-feeding. According to the mothers, $70 \%$ of the fathers in the control group and $51 \%$ of the fathers in the case group offered them effective support for breast-feeding, revealing a significant difference between the 2 groups $(P=.017)$.

At the time of the interview, 79 (52\%) mothers and 52 (43\%) fathers had psychiatric disorders (Table 2). The number of mothers diagnosed with mental disorders in the case group was around $11 \%$ higher than in the control group according to both the DSM-IV and the SRQ-20, but this difference was not statistically significant (Table 2). Similarly, no significant difference was observed between the 2 groups of fathers. Frequent arguing between the couple (present in 74 of them) and/or physical violence (present in 1 of the case couples and in 7 of the control couples) showed no statistical differences regarding the early cessation of breast-feeding $(P=.735$ and $P=.229$, respectively).

The percentage of maternal emotional and relational problems during puerperium (defined in this study as the first month after delivery and reported retrospectively) was $57 \%$ for mothers who were not breast-feeding and $37 \%$ for mothers who were still breast-feeding. There was a statistically significant association between weaning and maternal mental health problems in the puerperium (Table 3). The association remained close to significance in the multivariate logistic regression used to control the effects of maternal age, birth order, mother-child separation, and rooming-in (Table 4).

About $44 \%$ of the mothers and $37 \%$ of the fathers in the study population showed evidence of having had emotional and relational disorders in the past, with no significant difference between the groups (Table 3). Seventy-six percent of those mothers presenting emotional and relational functioning problems during the puerperium received a psychiatric diagnosis at 4 months postpartum. Twenty-four percent of the women did not have reported problems during the puerperium but presented disorders at 4 months (Table 5). 


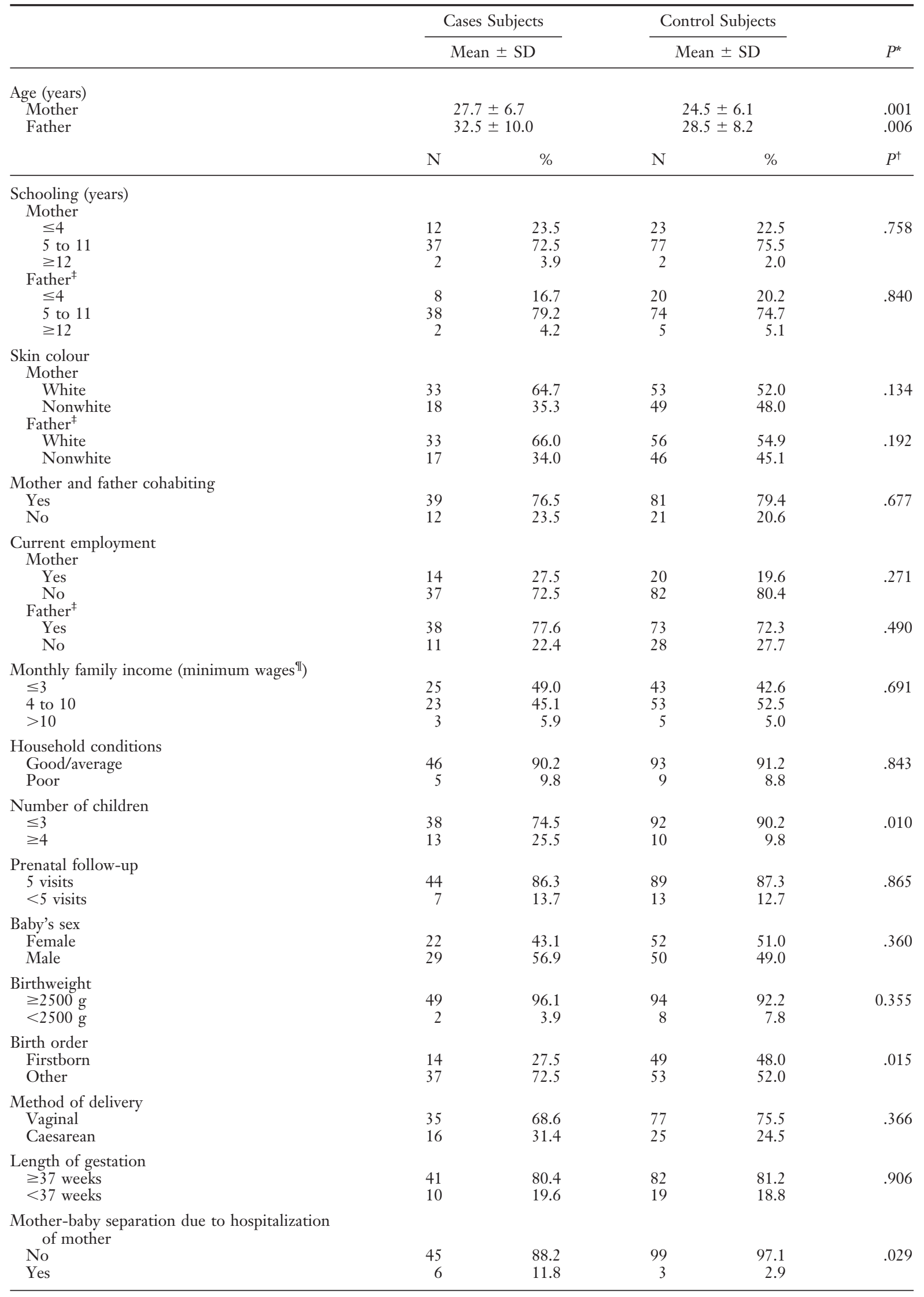




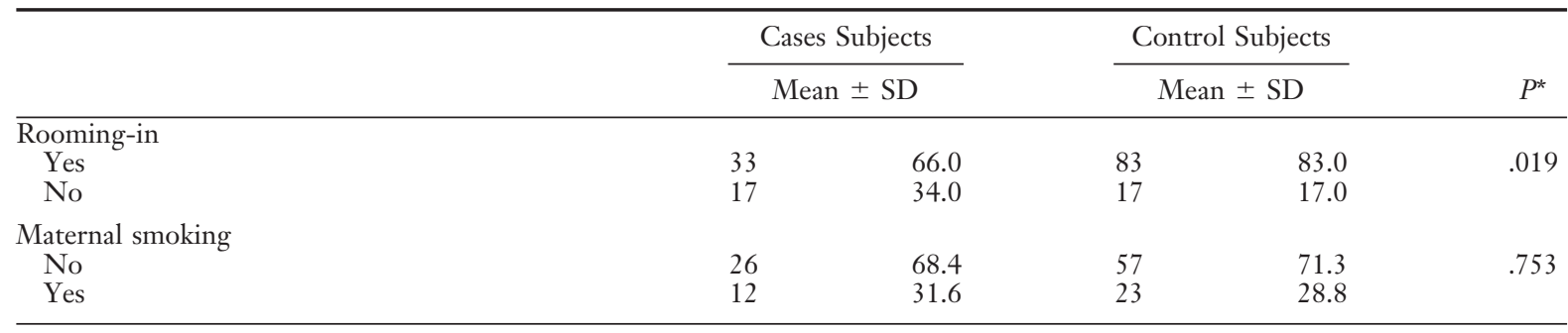

* Student's $t$ test.

$\dagger \chi^{2}$ test.

$\ddagger$ Number of fathers varies because some mothers could not give or refused to give information about non-cohabiting fathers.

II MW, minimum monthly wage in Brazil (about US \$70).

The most prevalent diagnostic category of parental mental disorder (Table 6) was depression. There was no statistical difference between case and control parents in terms of type of mental disorder. The mother's and father's mental health status in both groups were highly correlated re-

Table 2. Mental Diagnoses of Parents at the Time of the Study (According to DSM-IV Criteria and SRQ Scale)

\begin{tabular}{|c|c|c|c|c|c|c|c|}
\hline \multirow[b]{2}{*}{ Disorder } & \multicolumn{2}{|c|}{ Case Subjects } & \multicolumn{2}{|c|}{ Control Subjects } & \multicolumn{2}{|c|}{ Total } & \multirow[b]{2}{*}{$P^{*}$} \\
\hline & $\mathrm{N}$ & $\%$ & $\mathrm{~N}$ & $\%$ & $\mathrm{~N}$ & $\%$ & \\
\hline \multicolumn{8}{|l|}{ Mother (DSM-IV) } \\
\hline With disorder & 30 & 58.8 & 49 & 48.0 & 79 & 51.6 & \multirow[t]{2}{*}{.208} \\
\hline Without disorder & 21 & 41.2 & 53 & 52.0 & 74 & 48.4 & \\
\hline \multicolumn{8}{|l|}{ Father (DSM-IV) } \\
\hline With disorder & 18 & 47.4 & 34 & 41.0 & 52 & 43.0 & \multirow[t]{2}{*}{.509} \\
\hline Without disorder & 20 & 52.6 & 49 & 59.0 & 69 & 57.0 & \\
\hline \multicolumn{8}{|l|}{ Mother (SRQ) } \\
\hline$\geq 7$ (Disorder) & 22 & 43.1 & 32 & 31.4 & 54 & 35.3 & \multirow[t]{2}{*}{.151} \\
\hline$<7$ (No disorder) & 29 & 56.9 & 70 & 68.6 & 99 & 64.7 & \\
\hline \multicolumn{8}{|l|}{ Father (SRQ)† } \\
\hline$\geq 5$ (Disorder) & 7 & 18.9 & 13 & 15.7 & 20 & 16.7 & \multirow[t]{2}{*}{.658} \\
\hline$<5$ (No disorder) & 30 & 81.1 & 70 & 84.3 & 100 & 83.3 & \\
\hline
\end{tabular}

${ }^{*} \chi^{2}$ test.

$+\mathrm{n}=120$ because SRQ for 1 father was lost.

Table 3. Parents' Emotional and Relational Functioning during the First Month after Delivery and before Pregnancy (Modified GARF Scale)

\begin{tabular}{|c|c|c|c|c|c|c|c|c|}
\hline \multirow[b]{2}{*}{ Disorder } & \multicolumn{2}{|c|}{ Cases } & \multicolumn{2}{|c|}{ Controls } & \multicolumn{2}{|c|}{ Total } & \multirow[b]{2}{*}{$P^{*}$} & \multirow{2}{*}{$\begin{array}{c}\text { Odds ratio } \\
\text { (95\% CI) }\end{array}$} \\
\hline & $\mathrm{N}$ & $\%$ & $\mathrm{~N}$ & $\%$ & $\mathrm{~N}$ & $\%$ & & \\
\hline \multicolumn{9}{|l|}{ Mother (puerperium) } \\
\hline Moderate/severe & 29 & 56.9 & 38 & 37.3 & 67 & 43.8 & \multirow[t]{2}{*}{.021} & 2.22 \\
\hline None/mild & 22 & 43.1 & 64 & 62.7 & 86 & 56.2 & & $(1.12-4.40)$ \\
\hline \multicolumn{9}{|c|}{ Mother (before pregnancy) } \\
\hline Moderate/severe & 25 & 49.0 & 43 & 42.2 & 68 & 44.4 & \multirow[t]{2}{*}{.421} & \\
\hline None/mild & 26 & 51.0 & 59 & 57.8 & 85 & 55.6 & & \\
\hline \multicolumn{9}{|l|}{ Father (puerperium) } \\
\hline Moderate/severe & 15 & 39.5 & 24 & 28.9 & 39 & 32.2 & \multirow{2}{*}{.249} & \\
\hline None/mild & 23 & 60.5 & 59 & 71.1 & 82 & 67.8 & & \\
\hline \multicolumn{9}{|c|}{ Father (before pregnancy) } \\
\hline Moderate/severe & 15 & 39.5 & 30 & 36.1 & 45 & 37.2 & \multirow{2}{*}{.725} & \\
\hline None/mild & 23 & 60.5 & 53 & 63.9 & 76 & 62.8 & & \\
\hline
\end{tabular}

${ }^{*} \chi^{2}$ test. 
Table 4. Multiple Logistic Regression Analysis to Assess Association of Mother's Mental Health* during the First Month after Delivery and Weaning, Using after Controlling for Possible Confounding Variables

\begin{tabular}{|c|c|c|c|}
\hline Variables & Odds Ratio $†$ & $95 \%$ Confidence Interval & $P \neq$ \\
\hline Mother's age $\geq 21$ years & 2.92 & 1.02 to 8.37 & .046 \\
\hline Not firstborn & 1.71 & 0.72 to 4.08 & .228 \\
\hline Mother-baby separation & 5.03 & 0.93 to 27.17 & .061 \\
\hline No rooming-in & 2.04 & 0.84 to 4.98 & .116 \\
\hline $\begin{array}{l}\text { Mother's moderate/severe emotional and } \\
\text { relational functioning disorder in puerperium }\end{array}$ & 2.09 & 0.99 to 4.41 & .052 \\
\hline
\end{tabular}

* Modified GARF scale.

† Chance of breast-feeding termination before 4 months.

$\neq W$ ald $\chi^{2}$ test.

garding presence or absence of mental disorder $(P=0000)$ (Table 7). The simultaneous presence of mental disorders in both parents was not associated with interruption of breast-feeding before 4 months, even when the group was compared with the group of parents without disorders $(P=1.0)$.

\section{Discussion}

Little is available in the literature about the influence of mental health, especially the father's, on the duration of breast-feeding. The purpose of this study was to investigate this association. The study area, where starting breast-feeding is the expected norm, seemed to be a good setting for studying this issue. Our results revealed some relevant facts.

In Brazil, most women start breast-feeding (96\%) and the median duration of breast-feeding is 10 months. The prevalence of breast-feeding between 9 months and 1 year of age is $32.8 \%$. A study in Porto Alegre with a representative sample of all the children under 1 year of age showed a prevalence of breast-feeding of $71 \%$ and of exclusive breast-feeding of $22 \%$ among children between 3 and 4 months of age. Breast-feeding is not emphasized by the health system as a birth control method. ${ }^{33}$
The evaluation of mothers at 4 months postpartum, contrary to our initial hypothesis, did not reveal a statistically significant association between mental disorders and termination of breast-feeding, although we did find a higher number of mothers with problems in the group that had already interrupted breast-feeding. Mothers with any type of disorder were able to breast-feed at the same rate as women without a disorder. This seems to confirm the strength of the mother-baby bond and the power of maternal resilience, and it may reflect the appreciation of breast-feeding in the community, as reported in the literature. ${ }^{2}$ The lack of impact on breast-feeding of major conflict and physical violence coincides with the clinical impression of the authors that in very difficult marriages, often the woman clings to her baby, including breast-feeding it, as a means of getting emotional fuel. In addition, in our population, women often have a social network that supports them and breast-feeding. However, our sample is too small to draw definitive conclusions.

When the mother had problems during the first month after delivery, however, she was twice as likely to interrupt breast-feeding before 4 months. It seems, therefore, that the mental health status of

Table 5. Mothers' Emotional and Relational Functioning during the First Month after Delivery and at 4 Months Postpartum (Modified GARF Scale and DSM-IV)

\begin{tabular}{|c|c|c|}
\hline \multirow[b]{2}{*}{$\begin{array}{l}\text { Emotional Functioning } \\
\text { First Month after Delivery }\end{array}$} & \multicolumn{2}{|c|}{ Psychiatric Diagnostic Impression Four Months Postpartum } \\
\hline & $\begin{array}{l}\text { No/Mild Disorders } \\
\quad(\mathrm{N}=74)\end{array}$ & $\begin{array}{c}\text { Moderate/Severe Disorders } \\
(\mathrm{N}=79)\end{array}$ \\
\hline No or mild disorder $(\mathrm{n}=86)$ & $90.5 \%$ & $9.5 \%$ \\
\hline Moderate to severe disorder $(n=67)$ & $24.1 \%$ & $75.9 \%$ \\
\hline
\end{tabular}


Table 6. Psychiatric Diagnoses of Parents When the Baby Was 4 Months Old (According to DSM-IV Criteria)

\begin{tabular}{|c|c|c|c|c|c|}
\hline \multirow[b]{2}{*}{ DSM-IV } & \multicolumn{2}{|c|}{ Case Subjects } & \multicolumn{2}{|c|}{ Control Subjects } & \multirow[b]{2}{*}{$P^{*}$} \\
\hline & $\mathrm{N}$ & $\%$ & $\mathrm{~N}$ & $\%$ & \\
\hline \multicolumn{6}{|l|}{ Mother } \\
\hline Depression & 21 & 41.2 & 33 & 32.4 & .451 \\
\hline Anxiety & 5 & 9.8 & 8 & 7.8 & \\
\hline Alcohol abuse & 2 & 3.9 & 1 & 1.0 & \\
\hline Mental retardation & 2 & 3.9 & 4 & 3.9 & \\
\hline Other disorders & 0 & 0.0 & 3 & 2.9 & \\
\hline Without disorder & 21 & 41.2 & 53 & 52.0 & \\
\hline \multicolumn{6}{|l|}{ Father } \\
\hline Depression & 10 & 26.3 & 18 & 21.7 & .429 \\
\hline Anxiety & 4 & 10.5 & 3 & 3.6 & \\
\hline Alcohol abuse & 4 & 10.5 & 8 & 9.6 & \\
\hline Mental retardation & 0 & 0.0 & 3 & 3.6 & \\
\hline Other disorders & 0 & 0.0 & 2 & 2.4 & \\
\hline Without disorder & 20 & 52.6 & 49 & 59.0 & \\
\hline
\end{tabular}

${ }^{*} \chi^{2}$ test.

the mother when breast-feeding is being established may influence the continuation of breastfeeding. The high rate of persistence of maternal mental disorders appearing during puerperium emphasizes the need for early diagnosis and therapeutic intervention. The postpartum period has been reported as being the period during which women are at highest risk of developing mental disorders because of the multiple physical, emotional, and relational changes that have to be faced after the baby is born. ${ }^{16}$

Paternal mental problems were also very frequent but not associated with early weaning. We found a higher rate of fathers with disorders at 4 months postpartum (43\%) than in puerperium $(32 \%)$, which is in agreement with findings reported in 2 other studies that father's disorders tend to increase during their child's first year of life. ${ }^{23,26}$ These findings could be associated with the fact, evidenced in the clinical practice of the authors, that at 4 months, the father-baby 'honeymoon' has lost its intensity, whereas the intensity of the mother-child relationship persists, with a relative exclusion of the father. Some of the negative changes affecting mothers in the postpartum period, such as those in the sleep routine, also affect fathers, who face additional demands as providers but receive less attention from their wives. Support from the social network tends to decrease, and this may force the father to face more closely his role as provider and protector, as well as his personal limitations. This becomes even more difficult when the mother suffers from a mental disorder. One interesting finding, in accordance with the literature, was that mothers who felt that their husbands actively supported breast-feeding (talking about its importance, praising her, or facilitating her actions) were able to breast-feed for a longer period. ${ }^{34,35}$

Although this study was not designed to investigate prevalence (either of breast-feeding or of psychiatric diagnoses), we did observe a high frequency of mental disorders $(52 \%$ of the mothers and $43 \%$ of the fathers). In addition, $44 \%$ of the mothers and $37 \%$ of the fathers had a history of psychiatric disorders. These percentages are higher than those previously reported ${ }^{23,26}$ and suggest that postpartum psychiatric disorders in some parents may represent a continuation of a history of mental problems. Of those mothers and fathers with mental disorders, most were diagnosed as suffering from depression, as previously observed in several studies published in various countries. The prevalence of depression in our sample was higher than in the general population of Porto Alegre, which has been estimated, with another method, at $17 \%$ for women and $9.3 \%$ for men. ${ }^{30}$

Among the possible methodological limitations of this research, it is important to underscore the

Table 7. Association between Mother's and Father's Mental Health at 4 Months Postpartum (According to DSM-IV Criteria)

\begin{tabular}{lccc}
\hline & \multicolumn{2}{c}{ Paternal Mental Health* } \\
\cline { 2 - 3 } & $\begin{array}{c}\text { Without Psychiatric } \\
\text { Disorder }(\mathrm{n}=69)\end{array}$ & $\begin{array}{c}\text { With Psychiatric } \\
\text { Disorder (n }=12)\end{array}$ & $P^{+}$ \\
\hline Maternal Mental Health & & $23.1 \%$ & .000 \\
Without psychiatric disorder $(\mathrm{n}=61)$ & $71.0 \%$ & $76.9 \%$ & \\
With psychiatric disorder $(\mathrm{n}=60)$ & $29.0 \%$ & & \\
\hline
\end{tabular}

* Only 121 fathers were interviewed.

$\dagger \chi^{2}$ test. 
high number of families that were identified as eligible but could not complete the study, and were thus replaced by others. It is also important to remember that participation is more difficult when the involvement of the whole family is required. We compared the families that did not complete the study with those that did, and we found no significant differences in terms of the variables associated with breast-feeding. The fact that this was a case-control study, combined with the results of this comparison, indicates that our results were probably not affected by such limitations. The nature of the phenomenon under study-breast-feeding-prevented us from performing a double-blind study, but the possible bias resulting from this fact was minimized by the 2 interviewers' gathering a large amount of data and not knowing the main research question, their independent evaluations, and the participation of 2 informants (mother and father). The retrospective self-evaluation of maternal emotional and relational functioning is another possible limitation, but unreliability was limited by the inclusion of at least 2 informants and 2 evaluators to measure events that had occurred only 3 months before the interview. Checking the information reported by the mother with the father and vice versa also minimized the bias that could be associated with self-reporting.

We chose to use the SRQ-20 because it is selfadministered by the subjects, and thus provided a more objective measure, and because it has been validated for Brazilian Portuguese, which is not the case of the Edinburgh Postnatal Depression Scale (EPDS) used in most studies (at the time, it had been validated in Portugal in a population with different characteristics). Our results are therefore not always comparable with those of studies using the EPDS, although they tend in the same direction. The use of the SRQ-20 is also justified by the fact that it is often used in studies concerning primary health care. It is important to stress that, although the results provided by the SRQ-20 regarding prevalence were different from those found with the DSM-IV, the general results regarding associations were very similar. In the discussion of results, we chose to refer mostly to the DSM-IV clinical diagnoses (and not SRQ-20 results) because we considered them to be more methodologically sound and thus more accurate. In the population we studied, there was an identifiable tendency, especially among men, to undervalue emotional com- plaints. Because the use of the SRQ-20 depended on the subjects admitting to having symptoms and complaints, this may explain the fact that the differences in prevalence between the 2 methods were $16 \%$ for the women and $26 \%$ for the men. In the analysis, we gave more emphasis to the psychiatric diagnostic impression based on DSM-IV criteria using data and observations we could only get in the present. To assess the emotional and relational functioning in the puerperium and before pregnancy, we used an adaptation of the GARF scale based on the assessment of at least 2 respondents.

We believe that the present results can be generalized to families whose characteristics and culture are similar to those of the study population.

The high prevalence of psychiatric disorders in both parents in the postnatal period, the association between maternal mental disorder during puerperium and early interruption of breast-feeding, and the strong persistence of maternal problems at 4 months postpartum highlight the need to prepare health service providers for the early identification of psychiatric problems. We believe that it is possible to train health teams at the various levels of health care, including primary care, to provide competent and sensitive care to babies, their mothers, fathers, and families.

\section{Key Points for Clinicians}

1. Maternal psychiatric problems during the first month after delivery are associated with a 2 times higher chance of early termination of breast-feeding.

2. Eighty percent of the mothers presenting a psychiatric problem during the first month after delivery continue to show difficulties 4 months later.

3. Four months after the delivery mothers that were successful at establishing breast-feeding continue it, in this culture setting, regardless of their psychiatric status.

4. Mother's mental health is highly correlated with father's mental health. A high prevalence of psychiatric disorders was found.

We acknowledge the editorial support provided by the Research Graduate Group (GPPG) at Hospital de Clínicas de Porto Alegre. We thank Vanda Leite, MD, and Lisiane Perico, RN, from GHC and the following family therapists (Alceu Correia Filho, Angela Diehl, Claudia Baratojo, Carmen Fernandes, 
Daniela Domingues, Denise Jong, Elizabeth Wartchow, Iara Sotto Mayor, Izabel Sperb, Jeane Laronda, José Ovidio Waldemar, Lucy Bugs, Mara Rossato, Marcia Tomazi, Maria Cristina Jung, Marina Netto, Paulina Silbert, and Regina Palma) medical students (Anelise Cancelli, Antônio de Barros Lopes, Camila Giugliani, Carolina Alboim, Clarice Ritter, Daniel Barbosa, Guilherme Polanczyk, Jeber Ammar, Karina Marramarco, Letícia Quarti, Marta Pereira Lima, Martina Hoblik, Mauricio Kunz, Silvia Kelbert, and Tazio Vanni), and statisticians (Mathias Bressel and Vania Naomi Hirakata) for their support with data collection and analysis.

\section{References}

1. Cooper PJ, Murray L, Stein A. Psychosocial factors associated with the early termination of breast-feeding. J Psychiatr Res 1993;37:171-6.

2. Tarkka MT, Paunonen M, Laippala P. Factors related to successful breast feeding by first-time mothers when the child is 3 months old. J Adv Nurs 1999;29:113-8.

3. Galler JR, Harrison RH, Biggs MA, Ramsey F, Forde V. Maternal moods predict breastfeeding in Barbados. J Dev Behav Pediatr 1999;20:80-7.

4. Ribas D, Rubin F. Études des facteurs influant sur la fréquence, la durée, l'échec précoce de l'allaitement maternel, pour 1100 nourrissons parisiens. Neuropsychiatr Enfance Adolesc 1980;28:565-72.

5. Romino P. Postpartum depression and the experience of motherhood. Acta Obstet Gynecol Scand Suppl 1990;69:7-37.

6. Hannah P, Adams D, Lee A, Glover V, Sandler M. Links between early post-partum mood and postnatal depression. Br J Psychiatry 1992;160:777-80.

7. Alder EM, Cox JL. Breast feeding and post-natal depression. J Psychosom Res 1983;27:139-44.

8. Fleming A, Ruble DN, Flett GL, Shaul DL. Postpartum adjustment in first-time mothers: relations between mood, maternal attitudes, and motherinfant interactions. Dev Psychol 1988;24:71-81.

9. Kearney MH, Cronenwett LR, Barrett JA. Breastfeeding problems in the first week postpartum. Nurs Res 1990;39:90-5.

10. Hellin K, Waller G. Mothers' mood and infant feeding: prediction of problems and practices. J Reprod Infant Psychol 1992;10:39-51.

11. O'Hara MW, Schlechte JA, Lewis DA, Wright EJ. Prospective study of postpartum blues: biological and psychosocial factors. Arch Gen Psychiatry 1991; 48:801-6.

12. Holt GM, Wolkind SN. Early abandonment of breast feeding: causes and effects. Child Care Health Dev 1983;9:349-55.

13. Pop VJ, Essed GG, de Geus CA, van Son MM, Komproe IH. Prevalence of post partum depression-or is it post-puerperium depression? Acta Obstet Gynecol Scand 1993;72:354-8.

14. Alder E, Bancroft J. The relationship between breast feeding persistence, sexuality and mood in postpartum women. Psychol Med 1988;18:389-96.

15. Isabella PH, Isabella RA. Correlates of successful breastfeeding: a study of social and personal factors. J Hum Lact 1994;10:257-64.

16. Lawrence RA, Lawrence RM. Medical complications of the mother. In: Lawrence RA, Lawrence RM. Breastfeeding: a guide for the medical profession. 4th ed. St. Louis: Mosby; 1999. p. 550-61.

17. Trad PV. The emergence of psychopathology in a previously adaptive mother-infant dyad. Am J Psychoter 1990;44:95-106.

18. Misri S, Sinclair DA, Kuan AJ. Breast-feeding and postpartum depression: is there a relationship? Can J Psychiatry 1997;42:1061-5.

19. Susman VL, Katz JL. Weaning and depression: another postpartum complication. Am J Psychiatry 1988;145:498-501.

20. Scrimshaw SCM, Engle PL, Arnold L, Haynes K. Factors affecting breastfeeding among women of Mexican origin or descent in Los Angeles. Am J Public Health 1987;77:467-70.

21. Rohde LA, Busnello E, Wolf A, et al. Maternity blues in Brazilian women. Acta Psychiatr Scand 1997;95:231-5.

22. Essex C, Smale P, Geddis D. Breastfeeding rates in New Zealand in the first 6 months and the reasons for stopping. N Z Med J 1995;108:355-7.

23. Areias ME, Kumar R, Barros H, Figueiredo E. Comparative incidence of depression in women and men, during pregnancy and after childbirth. Validation of the Edinburgh Postnatal Depression Scale in Portuguese mothers. Br J Psychiatry 1996;169:30-5.

24. Kumar R, Robson KM. A prospective study of emotional disorders in childbearing women. Br J Psychiatry 1984;144:35-47.

25. Nordström UL, Dallas JH, Morton HG, Patel NB. Mothering problems and child morbidity amongst "mothers with emotional disturbances." Acta Obstet Gynecol Scand 1988;67:155-8.

26. Matthey S, Barnett B, Ungerer J, Waters B. Paternal and maternal depressed mood during the transition to parenthood. J Affect Disord 2000;60:75-85.

27. Giugliani E, Issler R, Kreutz G, et al. Breastfeeding pattern in a population with different levels of poverty in Southern Brazil. Acta Paediatr 1986;85: 1499-500.

28. Giugliani ERJ, Issler RMS, Justo EB, Seffrin CF, Hartmann RM, Carvalho NM. Risk factors for early termination of breast feeding in Porto Alegre, Brazil. Acta Paediatr 1992;81:484-7.

29. Kummer SC, Giugliani ERG, Susin LRO, et al. [Evolution of breastfeeding pattern.] Rev Saude $\mathrm{Pu}$ blica 2000;34:143-8.

30. Busnello ED, Pereira MO, Knapp WP, et al. Morbidade psiquiátrica na população urbana de Porto Alegre. J Bras Psiquiatr 1993;42 Suppl 1:55s-60s. 
31. Mari JS, William P. A validity study of a psychiatric screening questionnaire (SRQ-20) in primary care in the city of São Paulo. Br J Psychiatry 1986;148:23-6.

32. American Psychiatric Association. Diagnostic and statistical manual of mental disorders. 4th ed. Washington DC: American Psychiatric Association; 1994.

33. Ministério da Saúde do Brasil. Estudo da Prevalência de Aleitamento Materno nas Capitais Brasileiras e no Distrito Federal. Brasília: Ministério da Saúde; 2001.

34. Bar-Yam N, Darby L. Fathers and breastfeeding: a review of the literature. J Hum Lact 1997;13:45-50.

35. Sikorski J, Renfrew MJ, Pindoria S, Wade A. Support for breastfeeding mothers. Cochrane Database Syst Rev 2002;(1):CD001141. 